\title{
(RE)LENDO GÊNEROS, SEXUALIDADES E ESTADO NORMATIVO EM PELO MALO
}

\author{
(RE)READING GENDERS, SEXUALITIES AND \\ NORMATIVE STATE IN PELO MALO
}

Claudia Mayer"

Resumo: Pensar o cuír decolonial como projeto epistemológico na América Latina nos permite abordar uma gama crescente de questões urgentes acerca dos gêneros e sexualidades, que impactam fortemente as experiências não - e antinormativas, especialmente em contextos nacionais historicamente controlados por estados normativos. Neste trabalho, apresento uma análise da relação entre o estado normativo e a experiência da sexualidade dissidente no filme venezuelano Pelo Malo (2013), dirigido por Mariana Rondón. Para isso, fundamento minha análise na proposta de decolonização epistemológica constituída nos trabalhos de Gloria Anzaldúa, Walter Mignolo e Aníbal Quijano. Busco, através dessa análise, construir uma crítica à normatividade do Estado como é representado no filme para assim contribuir com o fortalecimento dos projetos de libertação epistemológica do Sul Global frente aos violentos avanços neoliberais.

PALAVRAS-CHAVE: cuír, decolonial, América Latina, heteronormatividade, racismo.

AвSTRACT: To think decolonial cuír as an epistemological project in Latin America allows us to address an ever growing range of urgent matters concerning genders and sexualities, which impact heavily on non- and counter-normative experiences, especially in national contexts historically controlled by normative States. In this essay I present an analysis of the Venezuelan film Pelo Malo (2013), directed by Mariana Rondón. For that, I ground my analysis on the idea of epistemological decolonization constituted in the works of Gloria Anzaldúa, Walter Mignolo, and Aníbal Quijano. This analysis aims at constructing a critique of the normativity of the State as it is represented in the film in order to contribute to the strengthening of epistemological liberation of the Global South in relation to current neoliberal advances.

KEYWORDs: cuír, decolonial, Latin America, heteronormativity, racism.

\footnotetext{
"Doutora em Estudos Literários e Culturais pela Universidade Federal de Santa Catarina. Co-coordenadora do Grupo de Pesquisa e Extensão Perspectivas Queer em Debate (PPGI/UFSC - Cnpq). Editora voluntária e integrante do conselho editorial da Editora Monstro dos Mares.Email: claudia.mayer@gmail.com
} 


\section{INTRODUÇÃo}

Neste artigo, revisito a análise do filme venezuelano Pelo Malo (dir. Mariana Rondón, 2013) que realizei em minha tese de doutora$\mathrm{do}^{1}$. Esse filme se utiliza do cabelo como local de convergência de muitos processos marginalizantes. Sobre ele pairam muitos significados, já começando pelo título: "cabelo ruim". De quem é, ou melhor, o que é esse "cabelo ruim"? O que ele faz e, principalmente, por que ele é tão ruim? Os processos de significação do cabelo vão surgindo de vários conflitos desenvolvidos no decorrer do filme: do desejo infantil de fantasiar-se para tirar uma fotografia ao esfacelamento de uma identidade nacional revolucionária contra o capitalismo; das hierarquias racistas e heteronormativas em operação na sociedade venezuelana ao prenúncio de uma homossexualidade latente e patologizada; da colonização e normalização dos corpos à performance da resistência cuír. No Estado entre a vida e a morte representa-

\footnotetext{
${ }^{1}$ Tese intitulada "Troubling Queer Metronormativity in Latin American Contexts: Intersectionality in Madame Satã, XXY, e Pelo Malo defendida em fevereiro de 2017 na Pós-Graduação em Inglês da Universidade Federal de Santa Catarina, na área de Estudos Linguísticos e Culturais, sob a orientação da Prof. Dra. Eliana de Souza Ávila. ${ }^{2} \mathrm{O}$ original "Pelo malo", que se tornou "Bad Hair" em tradução literal para o inglês, perde muito de seu sentido na tradução do título em português para "Cabelo rebelde". A expressão "cabelo ruim" existe no português brasileiro e se relaciona diretamente com o termo em espanhol, e por isso é perfeitamente pertinente aos temas desenvolvidos no filme. A escolha do título em português ecoa eufemismos racistas de presença inegável na sociedade atual, além de tirar a força da apropriação que o filme faz da expressão pejorativa ao manter ares de "politicamente correto" quando, na verdade, a expressão "cabelo ruim" continua a ser utilizada para perpetuar o racismo. Por que a escolha brasileira carrega esses eufemismos permanece uma questão interessante a ser explorada. Por tudo isso, escolho neste trabalho utilizar o título do filme no original em espanhol.
}

do em Pelo Malo, como se acometido de um mal tão difícil de ser vencido quanto o câncer do presidente', o "cabelo ruim" aparece múltiplas vezes representando a patologização e a marginalização de diversas performances não-normativas que se entrecruzam. Assim, a simbologia atrelada ao cabelo cria um espaço fronteiriço onde o cuír é "ferida aberta" (ANZALDÚA 1987, p. 25) pelos processos históricos de colonização, emancipação, expansão do capitalismo, socialismos, golpes de Estado, ditaduras, novas Repúblicas e neoliberalismo. Doutora em Estudos Literários e Culturais pela Universidade Federal de Santa Catarina.

Ecoa a concepção de que o cabelo é ruim, porém maleável: pode-se alisá-lo, arrumá-lo e até extingui-lo por completo, assim como a empreitada colonizatória assumiu como possível e, principalmente, legítimo o poder de exercer dominância sobre os povos e sobre cada indivíduo. Junto a isso, o filme também abre espaço para se ressignificar as sujeições que o cabelo vem a representar nas relações entre questões supostamente pessoais e irredutivelmente biológicas com o grande contexto das identidades nacionais, o Estado normativo e a formação do conhecimento hegemônico sobre os gêneros, as sexualidades, os processos de racialização, projetos econômicos e posicionamentos ideológicos. Por tudo isso, em Pelo Malo o cabelo se torna uma alegoria bastante representativa das várias maneiras como a manutenção do Estado executa e desenvolve relações de dependência com o controle dos nossos corpos.

\footnotetext{
${ }^{3}$ Chávez morreu em cinco de março de 2013 , meses antes do filme ser lançado no Festival de Toronto em 7 de setembro de 2013 .
} 
Meu objetivo neste artigo é prosseguir com a elaboração acerca da relação entre o Estado normativo e performances diversas de gêneros e sexualidades. Tomo como ponto de partida o modo como os gêneros e as sexualidades são representadas no filme de Rondón, procurando por traços da colonialidade do poder nas relações entre três personagens, Junior (Samuel Lange Zambrano), Marta (Samantha Castillo), e Carmem (Nelly Ramos). Isto é, em minha (re)leitura, procuro observar como se manifesta a herança colonial nos eixos que se referem ao controle do trabalho, ao processo de racialização dos povos, à formação de um mercado global(izado), e a imposição da lógica heteronormativa. Torna-se cada vez mais urgente que tais conexões sejam explicitadas, visto que o levante conservadorista que percebemos emergir nas relações nacionais e transnacionais se baseia fortemente no perpetuamento das relações hierárquicas forçosa e violentamente estabelecidas quando das empreitadas colonizatórias.

A colonialidade, que segundo Aníbal Quijano (2000) está presente na estrutura do poder hegemônico contemporâneo, se estabelece sobre quatro eixos: a ideia de raça e suas hierarquias, o controle sobre o trabalho, a formação de um mercado global, e a construção das noções de gênero e sexualidade (Lugones, 2007). Isso quer dizer que se criou uma diferenciação específica das pessoas do mundo, que as organizava em hierarquias de valor ao redor de suas raças e era fator determinante sobre a distribuição dos trabalhos disponíveis e do produto desse trabalho, assim como sobre as distribuições das identidades de gênero e sexualidade. Todo esse trabalho em reorganizar e ressignificar os corpos das pessoas, os locais, e as culturas foi o que fez funcionar a colonização dos povos e culturas não-Europeias. Pelo Malo nos mostra detalhes do quanto esses quatro eixos continuam interligados no momento geopolítico contemporâneo, e também quão complexos são seus mecanismos internos e implicações subjacentes. Por isso, ao analisar a relação entre gêneros, sexualidades, e o Estado, é imprescindível levar em conta as intersecções entre o que vemos como e a partir do cuír e como a colonialidade do poder vai aparecendo.

Visto que a formação dos Estados Nacionais se dá nos choques, nas rupturas e nas reconstruções constituídas nas relações colônia/Metrópole, é importante também ter em mente a distinção que Enrique Dussel (1977) faz das noções de "libertação" e "emancipação", sendo esta última aquela à qual Walter Mignolo (2007) adiciona os processos de decolonização. Enquanto processos emancipatórios mantêm as estruturas sociais, econômicas, culturais e de governo da metrópole, a decolonização busca desprender-se, desligar-se da colonialidade do ser, do poder e do conhecimento a fim de produzir alternativas à retórica da Modernidade, que se constitui através de um relacionamento dialético entre a Europa e seu(s) Outro(s) e, por isso, seguirá sempre lógicas e hierarquias binárias, excludentes e violentas. Por isso, quando falo em decolonização cuír, não me refiro a "desfazer" a significação de gênero e sexualidade coloniais e substituí-la por outra "mais abrangente" (ou assimilatória) 
ou proveniente de tentativas de resgatar passados que não podemos mais alcançar, tão eficaz a destruição de culturas não-Europeias. Falo em esforços que visam re-fazer o tecido de nossas relações a partir de uma crítica ao que as constitui e define, buscando nas alternativas hegemonicamente consideradas anormais, doentes, ou estranhas possibilidades de aliança para a desconstrução de padrões violentos, excludentes e totalitários.

A narrativa em Pelo Malo se passa durante um período crítico da Venezuela Chavista, quando a população fica sabendo que o então presidente Hugo Chávez ${ }^{4}$ está com câncer (que o levaria à morte pouco tempo depois). Nesse contexto, parte da população encena demonstrações de apoio ao presidente, raspando seus cabelos em praça pública como um gesto de solidariedade. A representação de tais manifestações traz para o filme a força do populismo do governo Chávez, que uniu sua imagem à do líder nacionalista venezuelano Simón Bolívar para mobilizar a população a favor de seu propósito de tomar o governo anterior e estabelecer um regime próprio, baseado nos ideais bolivarianos. Se Bolívar lutou pela independência da Venezuela, da Bolívia, do Equador, do Peru, da Colômbia e do Panamá, tirando-os do controle colonial espanhol, Chávez buscava estabelecer um governo que favorecesse as classes venezuelanas empobrecidas pela corrupção e exploração da elite política. Nota-se nas duas situações que, ocorrendo em momentos diferentes contextual e temporalmente, permanece a compreensão do poder binário colonial, em que um grupo é

${ }^{4}$ Hugo Chávez governou a Venezuela de 1999 a 2013. explorado por outro em troca de riqueza e outros privilégios.

Além disso, ao evocar a figura de Bolívar, Chávez alimenta uma persona messiânica, capaz de "libertar" aquelas pessoas cujas vidas são precarizadas pelo capitalismo. Entretanto, seu governo, como é representado no filme, não aponta para a "libertação", muito menos para alternativas além do binarismo colonial. Pelo Malo; ao invés disso, pode-se ler na crítica ao governo durante o filme que sem a emancipação da própria lógica de poder binária, o destino da assim chamada liberdade acaba sendo a decrepitude daquela mesma sociedade que se almejava salvar. Notadamente ausente do filme como personagem visível e ativo, mas pesadamente presente nas consequências de seu governo, $o$ (des)materializado Hugo Chávez de Pelo Malo faz ecoar a miseravelmente frustrada retórica salvacionista da modernidade e, assim, repete a lógica da colonialidade (Mignolo, p. 463-4). Substituir um polo do binário por outro não representa garantia de solução para os grandes problemas sociais do país.

\section{RESistêNCIA CUÍR NO ENTRELUGAR DO FILME}

Tal como Chávez está ausente da narrativa, também o está a possibilidade de performatividade cuír, já que durante o filme tais performances são interrompidas bruscamente. Cada vez que Marta percebe que Junior está tentando alisar o cabelo, quando ele fala sobre isso, canta uma música no ônibus, ou tira do bolso uma fivela que pegou da amiga, ela entra em pânico homofóbico. Para ela, certas particularidades do 
comportamento do menino são indicativas de efeminação e homossexualidade. Pela maneira que Marta reage, a homossexualidade (ou a sexualidade de maneira geral, como vamos percebendo no decorrer do filme) é algo que complicaria bastante as coisas. É possível imaginar que, na visão que Marta desenvolveu devido às suas experiências, a experiência livre da sexualidade apresente perigos à sobrevivência. Por exemplo, por ser mulher, ela não consegue sustentar as duas crianças e não vê muitas perspectivas para si mesma, a não ser se prostituir para o ex-chefe para conseguir algum dinheiro e seu emprego de volta. Tal situação demonstra que o mercado de trabalho é, inegavelmente, generificado. Se no começo ela resistia e procurava encontrar um emprego por seus próprios méritos, após uma evidente ocorrência de machismo ao ser recusada como segurança em um lava-carros, é patente para ela e para nós que o gênero é parte integrante dos mecanismos que controlam a distribuição do trabalho e, consequentemente, do capital financeiro para manter a vida.

Observando a trajetória de Marta buscando um emprego, pode-se notar que não são os "méritos" que alguém possa vir a ter que regem o mercado de trabalho. Se prestamos atenção à intersecção da homossexualidade com o mercado de trabalho, penso que não há o que se estranhar na descrença de Marta, seu desespero frente à possibilidade de ter um filho efeminado ou não-hetero. Além da dificuldade em arrumar um emprego por ser uma mulher, as poucas opções disponíveis são muito restritas. O que restaria ao menino efeminado? Durante uma conversa entre
Marta e Carmem, avó do menino, as mulheres demonstram saber sobre a precariedade da vida de meninos efeminados. A violência homofóbica está nas ruas, nas gangues, no Estado, e deve estar na escola também, o espaço que Junior está prestes a recomeçar a frequentar. São perigos que se equivalem: ou Junior raspa o cabelo para eliminar a vontade de alisa-lo e os significados desse alisamento, ou fica fora da escola, o que pioraria ainda mais sua situação em relação ao trabalho. $O$ racismo, a homofobia, e as relações trabalhistas se entrelaçam de tal maneira que a ideia de meritocracia ${ }^{5}$ que se propaga atualmente se desmancha com facilidade. Em seu lugar destaca-se a intrincada rede de poder que constrange as possibilidades de vir a ser e as distribui diferencialmente entre as pessoas.

Sem entrar na importante questão da homossexualidade como um "vício burguês" que chega furtivamente como importação cultural indesejada das nações imperialistas, como já foi vista em outros governos totalitários de esquerda na América Latina ${ }^{6}$, me pergunto sobre a total ignorância acerca da homossexualidade que impera entre as personagens. Tal ausência toma um ar neoliberal quando pensamos que, como argumento em minha tese, o filme silenciosamente e

\footnotetext{
${ }^{5}$ Vale lembrar que o termo "meritocracia" surge em 1958, em obra uma de ficção distópica escrita pelo sociólogo britânico Michael Young intitulada The rise of the meritocracy. Na obra de Young, a meritocracia ajuda a manter o desequilíbrio social ao ignorar os privilégios que dão suporte àqueles considerados portadores de mais méritos. Tal visão fictícia não está muito longe do atual apagamento de privilégios praticado pelos grupos que defendem a meritocracia, assim reforçando o silenciamento de injustiças históricas.

${ }^{6}$ Ver, por exemplo, o que diz acerca de Cuba Lourdes Martínez-Echazábal em artigo publicado neste dossier.
} 
por contraste projeta a solução para a economia destruída sobre uma nova economia de mercado, mais aberta, que o atual governo barrou. Assim, ao manter o neoliberalismo de fora, ficam fora também os progressos acerca do pensamento sobre a homossexualidade. Há uma conflação dessas duas partes em uma lógica simples em que o fim daquele modelo de estado e a instauração de um mais aberto, instaurado na e pela narrativa de progresso do neoliberalismo, tornam-se a solução que vai trazer benefícios econômicos e culturais. Mais uma vez, podemos notar a lógica salvacionista emergindo - desta vez, a salvação vindo como o neoliberalismo; no filme, uma salvação frustrada.

Há que se notar também a ausência de quaisquer outros personagens que desafiam a norma heterossexual; ao menos, não há nenhum que o faça abertamente. A impressão que se tem é de que a violência policial e a exclusão social imposta a transformistas e outras pessoas LGBT, como aponta Marcia Ochoa (2014) realmente exterminaram essa população e, por isso, Junior conta apenas com modelos heteronormativos de sexo e gênero para espelhar. Então, quando ele se olha no espelho e imita várias expressões corporais, Junior reproduz a noção binária de gênero automaticamente, pois não há nada além dela em seu horizonte de possibilidades. Nesse contexto em que só há o gênero masculino e o gênero feminino, não há as transformistas venezuelanas de quem fala Ochoa, por exemplo, pois o filme apresenta uma noção de gênero binária e fixa. Da mesma forma, o filme apresenta uma noção binária e fixa de sexualidade, funcionando no binário hetero/homo.
A resistência cuír aparece em Pelo Malo quando o filme acaba e os créditos finais começam a aparecer. Nesse entrelugar do filme, a diegese se fragmenta e coloca simultaneamente na tela a artificialidade do filme em forma dos créditos finais e um retorno ao mundo de Junior; não aquele do filme, que lhe coloca em "modo de espera" a descoberta da própria performance, mas um em que seu desejo se realiza e ele está vestido de cantor em um estúdio, cantando a música de Henry Stephen ${ }^{7}$. Por um lado, a localização desse momento fora do filme pode contribuir para o seu tom determinista, por outro lado a fantasia de Junior é feita possível junto à comunidade de nomes que se forma em torno dele, aquela comunidade de pessoas reais (quer dizer, que não são personagens fictícios) que produziu o filme e o tornou visível internacionalmente, chamando atenção para as questões LGBT na Venezuela. Os limites entre realidade e fantasia se complementam para construir uma potencialidade cuír num movimento de decolonização da produção fílmica, que está além das possibilidades epistemológicas do mundo apresentado no filme.

\section{Cuidado e (In)Capacidades}

Dentre as mulheres, Carmem é a única que parece ter dinheiro suficiente para garantir certo conforto. Seus poucos bens, que incluem o "luxo" de um secador de cabelos,

\footnotetext{
${ }^{7}$ Henry Stephen é um dos primeiros roqueiros Venezuelanos e se tornou famoso na carreira solo com a canção "Limón, Limonero", que Junior canta no filme. Será interessante problematizar em trabalhos futuros o fato de que Henry Stephen representa uma cultura importada, cria do imperialismo cultural que universalizava, à época, o rock and roll.
} 
parecem representar relíquias de uma época passada e melhor, quando havia mais conforto e discos de artistas que copiavam o que era moda nos Estados Unidos, como Henry Stephen. A caracterização de Carmem e seu apartamento constitui um espaço semissuspenso no tempo que evidencia as distinções entre o passado e o presente e apresenta a frustração do projeto desenvolvimentista imaginado para a República Bolivariana da Venezuela nos primeiros tempos da revolução.

No passado, talvez o marido de Carmem tenha sido soldado e isso lhe tenha garantido algum status e estabilidade financeira, quando a revolução ainda ardia. A imagem do soldado, o herói nacional revolucionário, reaparece no garoto negro que serve como um dos modelos de perfomance de gênero disponíveis para garotos no estúdio do fotógrafo. Mas os tempos são outros, os heróis do passado estão mortos ou morrendo - tanto o marido de Carmen, quanto o de Marta; o presidente Chávez em estágio terminal - e há meninos que não querem ser soldados, mas se arrumar e dançar. Há muito menos dinheiro, não apenas para pequenos luxos e distrações, como ouvir música ou usar produtos de beleza, como também para a própria sobrevivência.

Compreende-se por que Marta se sinta tentada pela ideia de vender o filho a Carmen, a avó que incentiva o alisamento do cabelo e costura a "roupa de cantor" que Junior quer usar. Para Marta, a efeminação de Junior é um perigo para ele mesmo, uma ameaça à sua sobrevivência; por isso, se esforça em heterossexualizá-lo, colocá-lo na escola, aproximá-lo das normas. Já Carmem vê a "inadequação" de Junior de maneira diferente. Como ele não pode ocupar nem o lugar do soldado, nem o de pai de família devido a todos os fatores que o "cabelo ruim" simboliza, Carmem se coloca à disposição para cria-lo junto com ela em seu refúgio, prometendo a ele uma vida um pouco melhor, na qual ele pudesse viver uma versão de sua cuiridade adaptada ao doméstico, ao cuidado - usualmente, atividades destinadas às mulheres. Marta ainda tem a idade e o corpo em que se deve continuar tentando virar-se sozinha, ser autônoma, mesmo que evidentemente necessite de auxílio e Junior represente uma possibilidade no futuro; já Carmem está velha, precisa de cuidados na velhice e vê em Junior alguém que pode dedicar-se a isso. Essa seria uma existência confinada à casa da avó, já que a rua representa muitos perigos para a sobrevivência cuír.

Mesmo assim, a casa da avó também apresenta seus riscos, como o da assimilação e domesticação, tanto no sentido de pertencer ao ambiente da casa quanto ao de passar a obedecer ordens e normas de comportamento dentro de uma lógica patriarcal. Em troca dessa aceitação condicionada, a cuiridade é (re)posicionada como assunto privado e aprisionada em casa, em nome da garantia de uma "sobrevida" que, ao mesmo tempo, reinscreve a cuiridade como incapacidade de sobreviver sem auxílios normatizantes e/ou assimilacionistas.

Nota-se que a distribuição de cuidados que pode ser observada nas decisões que Marta e Carmem querem tomar acerca de Junior segue a lógica colonial heteronormativa ao reinscrever os cuidados 
com os integrantes do núcleo familiar às mulheres e sua manutenção financeira como responsabilidade de seus integrantes do sexo masculino. Mesmo que essa responsabilidade não seja exclusiva dos homens, o mercado de trabalho é para eles menos desafiador do que para mulheres e para performances de gênero dissidentes. Os cuidados também não são papel do Estado, ao que tudo indica: não há provimento de auxílio para pessoas desempregadas como Marta, não há creches para as crianças nem cuidados para idosos. Além disso, também não é papel do Estado representado no filme a garantia de segurança para as presenças cuír nas ruas e nas instituições. É, entretanto, necessário que os indivíduos satisfaçam alguma das posições hetero e/ou homonormativas disponíveis nas representações de identidade nacional a fim de que o Estado exista, e isso é imposto aos indivíduos.

Pelo Malo representa um Estado omisso e quebrado, um Estado criticamente doente e incapaz de cuidar de seus próprios cidadãos, mesmo que imponha como seu papel regular sua materialização. As instituições que deveriam cuidar das pessoas (e ao mesmo tempo normalizá-las de acordo com os ideais do Estado) estão caindo aos pedaços e só sobrevive nelas o preconceito impregnado nas estruturas e nas práticas, tensionadas ao máximo para se manter dominantes frente ao próprio esfacelamento. Decolonizar a lógica dos cuidados e da sobrevivência se mostra mais uma questão urgente, pois a distribuição das responsabilidades segue normas desiguais e opressivas. As (in)capacidades, as diferenças e a diversidade podem até ser incorporadas ao imaginário hegemônico, porém em versões suavizadas, que lhes esvazia o potencial político. Relações entre Estados também entram em dinâmicas patologizantes, seja na forma de auxílios financeiros internacionais, seja no envio de tropas a áreas de conflito. Se a ideia de cuidado se baseia na dinâmica binária entre quem precisa de cuidado e quem pode dispensá-lo, então estamos articulando a lógica colonial que traz consigo os significados de dívida, dependência, controle, progresso, normalização, silenciamento, que adoecem as pessoas e suas formas de governo.

\section{Considerações FINAIS}

Pelo Malo apresenta um complexo retrato social que demonstra como a cuiridade relaciona a raça, a posição geopolítica, e a performance de sexo e gênero de alguém. Não podemos discuti-los separadamente porque se entrecruzam; além disso, nós as excedemos o tempo todo, o que torna estabelecer contornos bem definidos bastante complicado. O desligamento da lógica binária não é, de fato, a substituição de uma forma de pensar por outra nem a inversão de hierarquias, pois vemos que na prática os binários sustentam uns aos outros e estão em constante recriação. Por algum tempo, eu li o filme como determinista, fechado à possibilidade cuír. Marta, por exemplo, é uma personagem forte, ciente de estar com as mãos atadas por ser mulher. Saber disso, no entanto, não dá a ela o poder de deixar de reproduzir as normas que a oprimem, de criar novas relações com sua família e vizinhança. Junior, em outro exemplo, abre mão do cabelo para 
entrar na escola, simbolicamente deixando o cuír de lado. Após a análise que apresento neste artigo, começo a pensar que as personagens resistem tentando repetir as normas, porque se pararem de repeti-las vão deixar de existir simbólica e materialmente. Além disso, a repetição exaustiva dessas normas expõe sua arbitrariedade e absurdo, e essa é a única arma da qual as personagens dispõe.

A diversidade vem sendo assimilada e destituída de conteúdo político, tornando-se mais uma estratégia para continuar movendo o sistema capitalista de consumo. Apesar de presente no imaginário hegemônico, essa é uma diversidade posta em ordem por regras de convivência e r(a)epresentação. Então, por mais que não nos vejamos em um contexto como o de Pelo Malo, onde não há nenhuma forma de "diversidade" com a qual Junior possa se identificar, estamos muitas vezes lidando com imagens midiáticas rasas da diversidade, que ao invés de expor as marginalizações, as esconde sob o véu da normalização. É preciso que a resistência à assimilação e ao apagamento das diferenças seja constante, e que nos envolvamos em práticas alheias à lógica colonial a fim de reconstruirmos a autonomia sobre nossas identidades.

\section{REFERÊNCIAS}

ANZALDÚA, Gloria. Borderlands / La Frontera. $3^{a}$ ed. São Francisco: Aunt Lute Books, 1987.

MIGNOLO, Walter D. Delinking. The rhetoric of modernity, the logic of coloniality and the Grammar of de-coloniality. Cultural Studies, v. 21 n. 2-3, Mar/Abr 2007.
OCHOA, Marcia. Queen for a Day: transformistas, beauty queens, and the performance of femininity in Venezuela. Durham: Duke University Press, 2014.

Pelo Malo. Dir. Mariana Rondón. Sudaca Films, 2013.

QUIJANO, Aníbal. Modernidad, colonialidady América Latina. Neplanta. Views from South, v. 1, n. 3 .

Recebido para publicação em 29 out. 2017. Aceito para publicação em 17 nov. 2017. 